\title{
Pengaruh Pemberian Inhalasi Aromaterapi Lemon Citrus Terhadap Penurunan Nyeri Persalinan Kala I Fase Aktif
}

\section{Sonya Soraya}

Program Studi Magister Ilmu Kebidanan, Fakultas Kedokteran, Universitas Padjadjaran

Corresponden author: sonyasoraya15295@gmail.com

Received : 24 Agustus $2020 \quad$ Accepted : 29 September $2021 \quad$ Published: 30 September 2021

DOI: https://doi.org/10.37012/jik.v13i2.653

\begin{abstract}
ABSTRAK
Nyeri persalinan merupakan hasil dari interaksi fisiologi persalinan dan faktor psikologis. Sebagian besar persalinan (90\%) disertai nyeri, bahkan sampai nyeri berat. Nyeri yang tidak dapat ditoleransi oleh ibu dapat membuat ibu stress mengakibatkan impuls nyeri bertambah banyak dan lemahnya kontraksi otot rahim sehingga terjadi persalinan lama. Hal ini dapat mengakibatkan distress pada bayi. Aromaterapi merupakan salah satu metode nonfarmakologis untuk mengurangi nyeri persalinan. Aromaterapi lemon citrus adalah jenis aromaterapi yang dapat digunakan untuk mengatasi nyeri dan cemas. Tujuan dari penelitian ini untuk mengetahui adanya pengaruh pemberian inhalasi aromaterapi lemon citrus terhadap nyeri persalinan kala I fase aktif. Jenis penelitian yang digunakan adalah quasy experiment design. Jenis rancangan yang digunakan adalah one grup pretest posttest di di BPM Bidan D Kota Cimahi 2016. Sampel diambil secara Accidental sampling dari ibu bersalin yang memenuhi kriteria inklusi. Data dianalisis secara univariat dengan menggunakan mean dan standar deviasi, bivariabel dengan uji statistik Dependen T test. Hasil penelitian bahwa terdapat pengaruh pemberian inhalasi aromaterapi lemon citrus terhadap penurunan nyeri persalinan kala I fase aktif. Perbedaan ratarata skala nyeri persalinan diuji menggunakan uji t dependen mendapatkan hasil nilai $p$ value 0,009 .
\end{abstract}

Kata Kunci : Aromaterapi Lemon Citrus, Inhalasi, Nyeri Persalinan.

\begin{abstract}
Pain labor is a result from labor physiology interaction and physyological factors. Most deliveries (90\%) accompanied by pain, even up to severe pain. Pain that cannot be tolerated by the mother can make she feeling stress.It cause more pain impulses and weak uterine muscle contraction resulting prolonged labor. That will lead to fetal distress. Aromaterapi is one of non-pharmacological method to reduce labor pain. Lemon citrus essential oil is a kind of oil that can be used to reduce pain and anxiety. The objective of this study was identified the effect of lemon citrus aromatherapy inhalation with pain labor in the first stage of labor. This study use quasy experimen design with one grup pretest posttest approach at BPM midwife D in Cimahi City 2016. Sample were obtained through Accidental sampling from parturient which fulfill inclusion criteria, they are 17 parturient. Data analysis used mean and deviation standard for univariate analysis and dependent T test for bivariate analysis. The result showed that there are any effect of lemon citrus aromatherapy inhalation with labor pain decrease in active phase of the first stage in labor. The diffrence mean from dependent t test was significant with $p$ value 0,0009 .
\end{abstract}

Keywords: Lemon Citrus Aromatherapy, Inhalation, Pain Labor. 


\section{PENDAHULUAN}

Persalinan dan kelahiran merupakan kejadian fisiologis yang normal. (Prawirohardjo,2010) Nyeri persalinan bukan disebabkan oleh proses yang patologi atau trauma namun nyeri persalinan merupakan hasil dari interaksi fisiologi persalinan dan faktor psikologis. (Marshall\&Raynor, 2014)

Nyeri persalinan merupakan nyeri akibat kontraksi miometrium disertai mekanisme perubahan fisiologis dan biokimiawi. Di samping faktor fisik, faktor psikologis dan emosi, motivasi juga mempengaruhi timbulnya nyeri persalinan. Sebanyak $90 \%$ persalinan disertai nyeri, bahkan sampai nyeri berat. Stres pada ibu akan menyebabkan pengeluaran hormon stres seperti katekolamin dan steroid sehingga mengakibatkan pengurangan aliran darah ibu ke janin. Nyeri yang tidak dapat ditoleransi oleh ibu dapat membuat ibu stress mengakibatkan impuls nyeri bertambah banyak dan lemahnya kontraksi otot rahim sehingga terjadi persalinan lama. Hal ini dapat mengakibatkan distress pada bayi. (Tarsikah dkk, 2012) Bidan dalam melaksanakan asuhan persalinan berkewajiban memberikan kebutuhan dasar ibu bersalin, salah satunya adalah pengurangan rasa sakit. (Nurasiah,dkk. 2012)

Dengan perkembangan ilmu pengetahuan, dikembangkan beberapa metode untuk meminimalkan dan atau menghilangkan rasa nyeri saat persalinan. Manajemen nyeri persalinan ada dua cara yang digunakan, yaitu secara Farmakologis dan non farmakologis. Metode non farmakologi memiliki beberapa kelebihan diantaranya tidak membahayakan bagi ibu maupun fetus, tidak memperlambat persalinan jika diberikan kontrol nyeri yang adekuat, dan tidak mempunyai efek alergi maupun efek negatif lain. Selain itu, metode non farmakologis juga dapat meningkatkan kepuasan selama persalinan karena ibu dapat mengontrol perasaannya dan kekuatannya. (Firdayanti, 2009)

Aromaterapi merupakan salah satu metode nonfarmakologis, yaitu terapi yang menggunakan essential oil atau sari minyak murni untuk membantu memperbaiki atau menjaga kesehatan, membangkitkan semangat, menyegarkan serta menenangkan jiwa dan raga. (Astuti\&Wijayanti, 2015)

Penelitian yang dilakukan oleh Namazi dkk pada 2014 membuktikan bahwa aromaterapi dengan menggunakan minyak essensial bunga citrus aurantium dapat mengurangi kecemasan pada kala I persalinan. Dalam penelitian Rafhani Rosyidah tahun 2015 didapatkan kesimpulan bahwa inhalasi aromaterapi citrus aurantium dapat menurunkan nyeri persalinan kala I fase aktif. (Namazi et al. 2014)

Aromaterapi lemon merupakan jenis aromaterapi yang dapat digunakan untuk mengatasi nyeri dan cemas. Zat yang terkandung dalam lemon salah satunya adalah linalool yang berguna untuk 
menstabilkan sistem saraf sehingga dapat menimbulkan efek tenang bagi siapapun yang menghirupnya. (Purwandari \& Sabrian, 2014)

Smith dalam Cochrane Database Of Systematic Reviews membuat kesimpulan bahwa penelitian tentang aromaterapi terhadap nyeri persalinan masih kurang, sehingga dibutuhkan penelitian lebih lanjut dengan harapan aromaterapi sebagai manajemen nyeri persalinan dapat direkomendasikan pada praktek klinik. Selain itu, penelitian aromaterapi citrus untuk manajemen nyeri persalian masih sedikit tidak sebanyak aromaterapi lavender. Berdasarkan hal tersebut penelitian ini dilakukan dengan tujuan untuk mengetahui pengaruh pemberian inhalasi aromaterapi lemon citrus terhadap penurunan nyeri persalinan kala I fase aktif. (Smith et al, 2011)

\section{METODE}

Rancangan penelitian yang digunakan dalam penelitian ini adalah quasy experiment dengan pendekatan one grup pretest posttest dengan menguji perubahan - perubahan yang terjadi setelah adanya eksperimen. (Notoatmodjo, 2010) Populasi dalam penelitian ini adalah ibu bersalin di BPM Bidan D di Cimahi periode 1 April - 11 Juni 2016. Pengambilan sampel dilakukan secara aksidental (Accidental) yang memenuhi kriteria inklusi yaitu sebanyak 17 orang.

Pengkajian intesitas nyeri akan dilakukan dengan menggunakan NRS (Numerical Rating Scale), pada 30 menit sebelum pemberian aromaterapi. Kemudian aromaterapi lemon citrus diberikan selama 30 menit dengan cara dihirup langsung dari kassa steril selanjutnya dilakukan penilaian kembali skala nyeri klien dengan NRS. (Judha dkk, 2012)

Alat yang dipakai dalam penelitian ini adalah aromaterapi Lemon Citrus 100\% pure essential oil diteteskan 1-3 tetes ke kassa steril. Analisis bivariat yang digunakan adalah uji T-dependen (dependent sample T-test/paired sample T-test).

\section{HASIL DAN PEMBAHASAN}

\section{Hasil}

Pengkajian intesitas nyeri dilakukan pada Ibu bersalin kala I fase aktif (pembukaan serviks 4-7 $\mathrm{cm}$ ), baik primipara dan multipara, kehamilan tanpa komplikasi, seperti hipertensi gestasional, preeklampsi ringan (PER), preeklampsi berat (PEB), dan perdarahan antepartum, presenstasi kepala, tidak dalam pengaruh analgetic, menyukai aroma lemon citrus serta bersedia menjadi sample penelitian. 
Tabel 1.

Distribusi Frekuensi Intensitas Nyeri Responden Sebelum Dan Sesudah Diberikan Aromaterapi Lemon Citrus

\begin{tabular}{ccccc}
\hline \multirow{2}{*}{ Skala Nyeri Responden } & \multicolumn{2}{c}{ Sebelum } & \multicolumn{2}{c}{ Sesudah } \\
\cline { 2 - 5 } & $\mathbf{n}$ & $\mathbf{\%}$ & $\mathbf{n}$ & $\mathbf{\%}$ \\
\hline Nyeri Hebat & 2 & 11,8 & 2 & 11,8 \\
Nyeri Berat & 11 & 64,7 & 11 & 64,7 \\
Nyeri Sedang & 4 & 23,5 & 4 & 23,5 \\
\hline Total & $\mathbf{1 7}$ & $\mathbf{1 0 0}$ & $\mathbf{1 7}$ & $\mathbf{1 0 0}$ \\
\hline
\end{tabular}

Sebagian besar nyeri responden sebelum dan sesudah diberikan aromaterapi lemon citrus adalah nyeri berat sebanyak 11 responden $(64,7 \%)$. Secara deskriptif memang tidak ada perbedaan skala nyeri pada sebelum dan sesudah intervensi. Namun, jika dilihat dari skor nyeri pada skala NRS terdapat perbedaan sebagai berikut :

Tabel 2.

Intensitas Nyeri Responden Sebelum dan Sesudah Diberikan Aromaterapi Lemon citrus Pada Ibu Bersalin Kala I Fase Aktif

\begin{tabular}{|c|c|c|c|c|c|}
\hline \multirow{2}{*}{ No. } & \multicolumn{2}{|c|}{ Skor Nyeri Sebelum } & \multicolumn{2}{|c|}{ Skor Nyeri Sesudah } & \multirow{2}{*}{ Penurunan } \\
\hline & Nominal & Kategorik & Nominal & Kategorik & \\
\hline 1 & 10 & nyeri hebat & 10 & nyeri hebat & 0 \\
\hline 2 & 8 & nyeri berat & 7 & nyeri berat & 1 \\
\hline 3 & 8 & nyeri berat & 8 & nyeri berat & 0 \\
\hline 4 & 9 & nyeri berat & 8 & nyeri berat & 1 \\
\hline 5 & 6 & nyeri sedang & 5 & $\begin{array}{c}\text { nyeri } \\
\text { sedang }\end{array}$ & 1 \\
\hline 6 & 10 & nyeri hebat & 10 & nyeri hebat & 0 \\
\hline 7 & 9 & nyeri berat & 9 & nyeri berat & 0 \\
\hline 8 & 8 & nyeri berat & 8 & nyeri berat & 0 \\
\hline 9 & 8 & nyeri berat & 8 & nyeri berat & 0 \\
\hline 10 & 6 & nyeri sedang & 5 & $\begin{array}{c}\text { nyeri } \\
\text { sedang }\end{array}$ & 1 \\
\hline 11 & 8 & nyeri berat & 8 & nyeri berat & 0 \\
\hline 12 & 8 & nyeri berat & 8 & nyeri berat & 0 \\
\hline 13 & 8 & nyeri berat & 7 & nyeri berat & 1 \\
\hline 14 & 6 & nyeri sedang & 6 & $\begin{array}{c}\text { nyeri } \\
\text { sedang }\end{array}$ & 0 \\
\hline 15 & 9 & nyeri berat & 8 & nyeri berat & 1 \\
\hline 16 & 8 & nyeri berat & 8 & nyeri berat & 0 \\
\hline 17 & 6 & nyeri sedang & 6 & $\begin{array}{c}\text { nyeri } \\
\text { sedang }\end{array}$ & 0 \\
\hline Mean & 7,94 & & 7,59 & & \\
\hline
\end{tabular}

Berdasarkan tabel 2 dapat diketahui bahwa berdapat 6 responden yang mengalami penurunan skor nyeri. Ada 2 responden yang mengalami penurunan 1 poin pada skala 9 menjadi 8 masih 
dalam kategori nyeri berat, ada 2 responden yang mengalami penurunan dari skala 8 menjadi 7 masih dalam kategori nyeri berat dan 2 responden mengalami penurunan dari skala 6 menjadi 5 namun masih dalam kategori nyeri sedang.

\section{Analisis Bivariat}

Berikut ini adalah hasil uji T-dependen (dependent sample T-test/paired sample T-test) yang digunakan untuk melihat keefektifan suatu intervensi dengan membandingkan 2 nilai mean pada satu kelompok.

\section{Tabel 3.}

Distribusi Rata-Rata Skala Nyeri Responden Sebelum dan Sesudah Pemberian Aromaterapi Lemon citrus

\begin{tabular}{|c|c|c|c|c|c|c|}
\hline Variabel & Mean & SD & SE & P Value & n & $\begin{array}{l}\text { Perbedaan } \\
\text { Mean }\end{array}$ \\
\hline $\begin{array}{l}\text { Skala nyeri sebelum } \\
\text { diberikan aromaterapi }\end{array}$ & 7,94 & 1,298 & 0,315 & & & \\
\hline $\begin{array}{l}\text { Skala nyeri setelah } \\
\text { diberikan aromaterapi }\end{array}$ & 7,59 & 1,460 & 0,354 & 0,009 & 17 & 0,35 \\
\hline
\end{tabular}

Hasil uji statistik didapatkan nilai $p=0,009$, hal ini menunjukan bahwa terdapat pengaruh pemberian inhalasi aromaterapi lemon citrus terhadap penurunan nyeri persalinan kala I fase aktif di BPM Bidan D Kota Cimahi 2016.

\section{Pembahasan}

Nyeri persalinan berbeda pada setiap wanita. Bagaimana ia mempersepsikan dan menginterpretasikan rasa nyeri dipengaruhi oleh berbagai faktor fisik, emosional, psikososial, budaya dan lingkungan. (Lowdermilk dkk, 2013)

Ketidaknyamanan atau sakit pada saat persalinan disebabkan oleh penurunan kepala janin ke dalam rongga panggul, tekanan pada servik serta peregangan pada dinding vagina dan otot bawah panggul yang disebabkan oleh penurunan dari bagian presentasi janin. (Marshall\&Raynor, 2014)

Pada saat persalinan, jika seseorang merasa takut dan panik maka otak akan mengalirkan zat yang menutup pengeluaran endorphin sehingga semakin luar biasa sakit yang dirasakan dan menyebabkan ibu menjadi stress dalam menghadapi persalinannya yang membuat impuls nyeri bertambah banyak dan lemahnya kontraksi otot rahim. (Rosyidah,2015)

Para peneliti dari The Ohio State University mengungkapkan bahwa aromaterapi minyak Lemon (Citrus Lemon) bisa meningkatkan mood, merelaksasikan pikiran dan meningkatkan konsentrasi. Lemon citrus juga memiliki kandungan Linalool dan Linalyl acetate yang berperan dalam aktivitas otak. Komponen zat ini akan merangsang sistem saraf simpatis 
dan nucleus Raphe yang mensekresi serotonin sehingga dapat meningkatkan konsentrasi, ketelitian, dan kewaspadaan. (Widyarto dkk, 2015)

Aromaterapi lemon citrus dapat digunakan untuk mengatasi nyeri dan cemas. Zat yang terkandung dalam lemon salah satunya adalah linalool yang berguna untuk menstabilkan sistem saraf sehingga dapat menimbulkan efek tenang bagi siapapun yang menghirupnya. Linalool dalam aromaterapi menyebabkan perasaan rileks, meningkatkan sirkulasi dan menghantarkan pesan elektrokimia ke susunan saraf pusat. Selanjutnya linalool ini akan menyebabkan spasmolitik serta menurunkan aliran impuls saraf yang mentransmisikan nyeri. Linalool berfungsi sebagai anxiolitic atau zat yang dapat menurunkan ansietas, aktifitas utamanya adalah meningkatkan kekebalan tubuh serta melancarkan sirkulasi dan meningkatkan respon eksitasi sel. Limonen yang terdapat dalam aromaterapi lemon citrus dapat menghambat prostaglandin sehingga dapat mengurangi nyeri. (Purwandari \& Sabrian, 2014)

Pada penelitian ini terlihat ada penurunan skor nyeri sesudah pemberian aromaterapi lemon citrus. Penelitian serupa telah dibuktikan oleh Rafhani Rosyidah (2015) bahwa aromaterapi dengan menggunakan minyak esensial citrus aurantium dapat mengurangi nyeri persalinan kala I fase aktif pada ibu bersalin.

Linalil asetat dalam aromaterapi lemon citrus sangat berguna untuk menormalkan keadaan emosi serta keadaan tubuh yang tidak seimbang, dan juga memiliki khasiat sebagai penenang serta tonikum, khususnya pada sistem saraf. Sehingga dapat disimpulkan bahwa aromaterapi lemon citrus merupakan jenis aroma terapi yang dapat digunakan untuk mengatasi nyeri dan cemas. (Purwandari \& Sabrian, 2014)

Efek aromaterapi sangat kompleks dan halus karena struktunya kompleks dan sifat kimianya. Mekanisme aksi aromaterapi melibatkan integrasi dari essential oil menjadi sinyal biologis dari sel-sel reseptor di hidung ketika dihirup. Sinyal ditransmisikan ke limbik dan bagian otak yaitu hipotalamus melalui bulb. Sinyal ini menyebabkan otak untuk melepaskan neuro messengers seperti olfactory serotonin, endorphin dll, untuk menghubungkan sistem saraf dengan sistem bagian tubuh lain yang diyakini ada perubahan yang diinginkan dan memberikan perasaan lega. (Ali et al, 2015)

\section{SIMPULAN DAN REKOMENDASI}

Berdasarkan hasil Penelitian dan Pembahasan dapat disimpulkan bahwa terdapat pengaruh pemberian inhalasi aromaterapi lemon citrus terhadap penurunan nyeri persalinan kala I fase aktif pada ibu bersalin dengan $p$ value 0,009. Tenaga kesehatan khususnya Bidan direkomendasikan untuk mempertimbangkan aromaterapi sebagai salah satu terapi 
komplemeter untuk manajemen nyeri persalinan. Selain itu untuk penelitian selanjutnya diharapkan dapat melakukan penelitian ini dengan jumlah responden yang lebih banyak, baik dengan metoda yang sama ataupun berbeda.

\section{REFERENSI}

1. Astuti, W., Rahayu, H. S. E., \& Wijayanti, K. (2015). Pengaruh Aromaterapi Bitter Orange Terhadap Nyeri Dan Kecemasan Fase Aktif Kala 1. In Prosiding Seminar Nasional \& Internasional

2. Ali, B., Al-Wabel, N. A., Shams, S., Ahamad, A., Khan, S. A., \& Anwar, F. (2015). Essential oils used in aromatherapy: A systemic Review. Asian Pacific Journal of Tropical Biomedicine, 5(8), 601-611

3. Firdayanti.(2009). Terapi Nyeri Persalinan Non Farmakologis. Jurnal Kesehatan Fakultas Ilmu Kesehatan UIN Allaudin Makassar, 2 (4), 8-10

4. Judha, dkk (2012). Teori Pengukuran Nyeri dan Nyeri Persalinan. Yogyakarta : Muha Medika

5. Lowdermilk, dkk. (2013).Keperawatan maternitas edisi 8.Singapore : Elsevier

6. Marshall\&Raynor.(2014).Myles textbook for midwives sixteenth ed.Chruchill Livingstone Elsevier

7. Namazi, Masoumeh et al.(2014). Aromatherapy With Citrus Aurantium Oil and Anxiety During the First Stage of Labor.Iran Red Crescent Med J, 16(6), 1

8. Notoatmodjo (2010). Metode Penelitian Kesehatan. Rineka Cipta, Jakarta

9. Nurasiah, dkk. (2012). Asuhan Persalinan Normal Bagi Bidan. Bandung: PT Refika Aditama

10. Prawirohardjo, S (2010) Ilmu Kebidanan, Jakarta : PT Bina Pustaka

11. Purwandari, F \& Sabrian, F.(2014). Efektifitas terapi aroma lemon terhadap penurunan skala nyeri pada pasien post laparatomi. Jurnal Online Mahasiswa Program Studi Ilmu Keperawatan Universitas Riau, 1(1), 1-6.

12. Rosyidah, Rafhani. (2015). Pengaruh Pemberian Inhalasi Aromaterapi Citrus Aurantium Terhadap Nyeri Persalinan Kala I Fase Aktif, tesis. Yogjakarta : Universitas Gadjah Mada. 
13. Smith, et al.(2011). Aromatherapy for pain management in labour (Review). Cochrane Database Syst Rev.Jul 6 (7)

14. Tarsikah dkk, (2012). Penurunan Nyeri Persalinan Primigravida Kala I Fase Aktif Pasca Penghirupan Aromaterapi Lavender. Majalah Kedokteran Bandung, Vol 44 (1)

15. Widyarto, dkk. (2015). Pengaruh Aromaterapi Lemon (Citrus Limon) Terhadap Waktu Reaksi Sederhana Pria Dewasa. Bagian Fisiologi Fakultas Kedokteran, Universitas Kristen Maranatha. 